\title{
Letter: Micro-RNA-125b and its use as a biomarker of systemic malignancies besides urothelial cancers
}

\author{
Shailendra Kapoor, MD
}

Mechanicsville, VA

Cite as: Can Urol Assoc J 2013;7:85. htrp://dx.doi.org/10.5489/cuaj.741

I read with great interest the recent article by Snowdon and colleagues. ${ }^{1}$ MiR-125b may serve as a biomarker in a number of systemic malignancies besides urothelial cancers.

For instance, in non- small cell lung carcinomas (NSCLC) miR-125b expression is a significant biomarker. In fact, miR$125 \mathrm{~b}$ expression in these malignancies is an independent determining factor of prognosis. Patients with NSCLC and high miR-125b levels typically exhibit a poor clinical outcome. ${ }^{2}$ Lower levels of miR-125b are seen in those with well differentiated tumours in comparison to those with poorly differentiated tumours. Patients with lung malignancies that do not respond to therapy typically exhibit higher levels.

Similarly, miR-125b influences clinical prognosis in colorectal malignancies. Progression of the primary tumour involves a direct involvement of miR-125b. miR-125b acts by attenuating p53 expression in the malignant cells. ${ }^{3}$ Colorectal carcinoma patients with high miR-125b levels typically have a poor clinical outcome in contrast to patients who express low levels of miR-125b. Individuals with high miR-125b expression develop larger tumours that exhibit greater invasiveness. These findings have been confirmed by Nishida and colleagues in a recent study. ${ }^{4}$

The above examples clearly illustrate the significance of assessing miR-125b levels in determining the prognosis in a number of systemic malignancies. There is a clear need for further studies to further explore the possible relationship of miR-125b with clinical prognosis in other systemic malignancies.

Competing interests: None declared.

\section{References}

1. Snowdon J, Boag S, Feilotter $\mathrm{H}$, et al. A pilot study of urinary microRNA as a biomarker for urothelial cancer. Can Urol Assoc J 2013;7:28-32. http://dx.doi.org/10.5489/cuaj.11115. Epub 2012 May 15.

2. Yuxia $M$, Zhennan $T$, Wei $Z$. Circulating miR-125b is a novel biomarker for screening non-small-cell lung cancer and predicts poor prognosis. J Cancer Res Clin Oncol 2012;138:2045-50. http://dx.doi. org/10.1007/s00432-012-1285-0. Epub 2012 Jul 18.
3. Cui EH, Li HJ, Hua F, et al. Serum microRNA 125b as a diagnostic or prognostic biomarker for advanced NSCLC patients receiving cisplatin-based chemotherapy. Acta Pharmacol Sin 2013;34:309-13. http:// dx.doi.org/10.1038/aps.2012.125. Epub 2012 Sep 17.

4. Nishida N, Yokobori T, Mimori K, et al. MicroRNA miR-125b is a prognostic marker in human colorectal cancer. Int J Oncol 2011;38:1437-43. http://dx.doi.org/10.3892/iijo.2011.969. Epub 2011 Mar 10.

Correspondence: Dr. Shailendra Kapoor, 74 Crossing Place, Mechanicsville, VA ; fax: 865-678-6787; shailendrakapoor@yahoo.com

\section{Response: Micro-RNA-125b and its use as a biomarker of systemic malignancies besides urothelial cancers}

\author{
D. Robert Siemens, MD, FRCSC \\ Department of Urology, Queen's University, Kingston, ON
}

Cite as: Can Urol Assoc J 2013;7:85-6. http://dx.doi.org/10.5489/cuaj.739

W e appreciate the letter from Dr. Kapoor regarding the potential of miRNA gene expression, and specifically miR-125b, to allow us to create a distinct cancer signature as part of our armamentarium for diagnosis and prognosis. ${ }^{1}$ Indeed, such epigenetic fingerprinting is a hot-topic. Although our pilot results in bladder cancer, and those of others, need much more extensive external validation it is perhaps even more important that we ask the questions that need to be answered. For example, we need biomarkers that allow us to determine those high-risk, nonmuscle invasive cancers that are not going to respond to intra-vesical BCG and require early cystectomy: not just the presence or absence of disease. As we continue to validate miRNA expression as a useful tool, we need to constantly focus our efforts on these clinically relevant endpoints.

Competing interests: None declared. 


\section{Reference}

1. Kapoor S. Letter: Micro-RNA-125b and its use as a biomarker of systemic malignancies besides urothelial cancers. Can Urol Assoc J 2013;7:85. http://dx.doi.org/10.5489/cuaj.741

Correspondence: Dr. D. Robert Siemens, Department of Urology, Kingston General Hospital, Queen's University, Kingston, 0N K7L 2V7; fax: 613-545-1970; siemensr@kgh.kari.net

\section{Hormonal assessment in clinically silent adrenal pheochromocytoma}

\author{
Behnam Shakiba, MD \\ Department of Urology, Mashhad University of Medical Sciences, Islamic Republic of Iran
}

Cite as: Can Urol Assoc J 2013;7:86. http://dx.doi.org/10.5489/cuai.260

read with great interest the case by $\mathrm{Li}$ and colleagues entitled "A case of clinically silent giant right pheochromocytoma and review of literature." ${ }^{\prime 1}$ The authors did not mention the hormonal and metabolic evaluation of adrenal incidentaloma. I would like to point out that National Institutes of Health consensus statement recommends metabolic testing for cortisol and catecholamine hypersecretion in all adrenal incidentalomas. ${ }^{2}$ I think if they tested the catecholamine metabolites before the operation, they could find the high level of catecholamine metabolites and confirm the diagnosis of pheochromocytoma preoperatively.
It is a very critical point and the International Symposium on Pheochromocytoma recommended that all patients with pheochromocytoma, including patients with clinically silent pheochromocytoma, should undergo preoperative catecholamine blockade. ${ }^{3}$ Some researchers reported a mortality rate of about $50 \%$ without routine initiation of preoperative catecholamine blockade. ${ }^{4}$

The authors also state that "In our case, the giant cystic mass was benign pheocrhomocytoma by histopathological evaluation." ${ }^{11}$ Although a number of pathologic criteria to differentiate benign pheochromocytoma from malignant ones have been proposed, to date, malignancy can only be confirmed by the presence of clinical metastases. Pathologic features and local invasion are of limited value in determining malignancy potential of an adrenal pheocrhomocytoma.

Competing interests: None declared.

\section{References}

1. Li C, Chen Y, Wang W, et al. A case of clinically silent giant right pheochromocytoma and review of literature. Can Urol Assoc J 2012;6:E267-9. http://dx.doi.org/10.5489/cuaj.11195

2. Young WF Jr. Clinical practice. The incidentally discovered adrenal mass. N Engl J Med 2007;356:60110. http://dx.doi.org/10.1056/NEJMcp065470

3. Pacak K, Eisenhofer G, Ahlman H, et al. International Symposium on Pheochromocytoma. Pheochromocytoma: recommendations for clinical practice from the First International Symposium. October 2005. Nat Clin Pract Endocrinol Metab 2007;3:92-102. http://dx.doi.org/10.1038/ ncpendmet0396

4. Pacak K, Linehan WM, Eisenhofer G, et al. Recent advances in genetics, diagnosis, localization, and treatment of pheochromocytoma. Ann Intern Med 2001;134:315-29.

Correspondence: Dr. Behnam Shakiba, Department of Urology, Mashhad University of Medical Sciences, Islamic Republic of Iran; b_shakiba@razi.tums.ac.ir 